\title{
Towards an Adaptive Learning System Based on Agile Learner-centered Design
}

\author{
Amal Battou \\ IRF-SIC Laboratory. Ibn Zohr University \\ Agadir. Morocco \\ Driss Mammass \\ IRF-SIC Laboratory. Ibn Zohr University \\ Agadir. Morocco
}

\begin{abstract}
Adaptive Learning concept has apprehended the interest of educational actors and partners, especially in higher education. However, the implementation of this concept has faced many challenges, particularly in Adaptive Learning Systems (ALS). The present paper aims to give the foundation of a framework for an ALS that gives extensive attention at each stage of the design process to the end-user: learners. The system proposed is based on Agile Learning Design approach and integrating learner-centered design to improve teaching effectiveness, facilitate learning among learners, encourage long life learning and maximize motivation as well as reducing the dropout rates.
\end{abstract}

Keywords - Teaching, learning, Agile learning design, learner-centered design, ALS.

\section{INTRODUCTION}

The uses of Adaptive Learning System (ALS) present many greater opportunities to support online learning and training from managing the learning and training process, through to monitoring assessment process, especially in higher education. Furthermore, the most ALS provide instructional content that can be specifically tailored to meet individual learner needs.

One of the challenges faced by developers of ALS has been how to design and create quality and pertinent ALS, able to build courses based on a model of the goals, preferences and knowledge of an individual user and use this throughout the interaction for adaptation to the needs of that user. This is due to the fact that ALS deal with diverse backgrounds, such as software developers, web application experts, content developers, domain experts, instructional designers, user modeling experts, pedagogues, etc. [1].

Moreover, the process of defining and developing e-learning material for an ALS is often expensive to produce especially in a single context setting- making the return on investment difficult to quantify [2].

The most of ALS currently available provide similar sets of features. The most of them are designed and developed from scratch, without taking advantages of the experience from previously developed applications, because the latter's design is not codified or documented [3]. Thus, development teams are wasting time and efforts to reinvent the wheel.

Various works have been presented in the literature in order to support the design of ALS [2][3][4][5][6]. Thus, there are several learning design methods presented in the literature, such as ADDIE, OULDI, Design thinking, Xproblem, etc. However, the most of them don't involve the learner until late in the project which is in our view an obstacle for the adaptation of the content to the features of the learner and leads to the dropout.

In this work, we focus on one of the recent works proposed to design ALS, which is called Agile Learning Design. This choice is based on a comparative study of the most used approaches in the literature that was subject of other publications [7][8]. A learner-centered approach -that is increasingly being encouraged in higher education- will be implemented to Agile Learning Design process to involve the learner in each stage of the design process.

The present work aims to present a framework for designing an ALS based on Agile Learning Design approach and integrating the learner-centered approach. The structure of the rest of this paper is as follows. The second section provides an overview of the concepts learning design, Agile learning design and learner centered approach. The third section discusses the interest of integrating learner centered approach into Agile learning design. The fourth section describes a case study based on Agile Learning Design approach and integrating the learner centered approach. The fifth section provides discuss of the preliminary results of this work. Finally, a conclusion and future work are presented in the last section. 


\section{BACKGROUND AND RELATED WORK}

In this section, we present first an overview of the concept of Learning Design. We provide afterwards a summary of Agile Learning Design and learner-centered design.

\section{A. Learning Design}

Historically, Learning Design has emerged from instructional design, but with a focus on learning activity as the central concern of the design process [9]. It was presented as a methodology for both articulating and representing the design process and providing tools and methods to help designers in their design process [10].

Koper [11] defines the Learning Design as the description of the teaching-learning process that takes place in a unit of learning (eg, a course, a lesson or any other designed learning event). Other authors [9] use the term designing for Learning which is defined as The process by which teachers - and others involved in the support of learning - arrive at a plan or structure or design for a learning situation.

Learning design representations enable teachers to document, model and share teaching practice at various levels: from the creation of a specific learning activity, through the sequencing and linking of activities and resources, to the broad curriculum and program levels.

\section{B. Agile Learning Design approach}

The Agile Learning Design is an iterative model of learning design that focuses on collaboration and rapid prototyping. Agile Learning Design can be adapted to fit the needs of the learning and training community by providing an ethos for the design of learning [12]. Several Agile methods have been presented and developed (SCRUM, Extreme Programming, Feature-Driven Development, etc.)

The flow of agile Learning Design may contain several cycle Fig.1 (see below). Each cycle consists of problem analysis in the first phase, followed by the development of a single feature of the final product. Once this single small part of your course is finished you can start testing and evaluating the efficiency and the return on investment of this part. If the results are satisfying a new iteration begins, until the course or the project are fully finished, otherwise the designer has to take one step back, understand what went wrong, and correct.

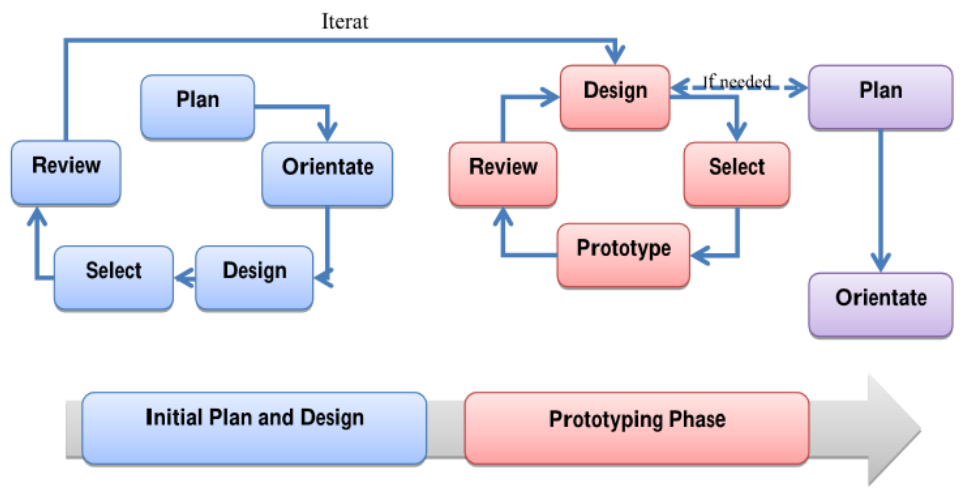

Figure 1. The flow of Agile Learning Design

In the literature, we find a variety of agile design practices. Each of these practices is important, and each is needed. The agile practices are combined with Learning Design, assisting and guiding the design and creation of learning environment [13]:

- Active users participation : Users are involved in the development process, helping to identify and solve problems and mistakes and providing rapid feedback to the team;

- Collaborative development: All team members constantly interact and communicate throughout the development process, promoting a collaborative and productive environment;

- Architecture/Design envisioning: Initial software architecture and requirements are designed at the beginning of a project to identify and think through critical issues;

- Iterative modeling/ design: Software functionalities are designed at the beginning of an iteration to identify team's strategy for that iteration;

- Model/ Design storming: Software functionalities are designed on a just-in-time (JIT) basis to reflect on specific aspects of team's solution; 
- Early and continuous Evaluation: Testing and validation activities are conducted at the beginning of the project and extend throughout the development process;

\section{Learner-centered approach}

The learner centered approach involves methods of teaching that move the emphasis of teaching from the instructor and contents to the learner. In the literature, the terms Learner-centered, learning-centered teaching or studentcentered learning, are commonly used to design this approach. The term learner-centered will be used through this work even if some authors use the other terms.

Several authors [14][15][16] when the focus becomes learner higher rates of student retention is attained and have better prepared graduates than those students who were more traditionally trained.

Moreover, Mattheu [17] claimed that adopting learner centered approach; learners are proactive independent, responsible for both what they learn and how they learn. The course provides a flexible framework, supportive environment and collaborative learning culture, with faculty guiding learners through their learning as mentors, with the focus on developing students' critical thinking, problem-solving and research skills. This enables them to become effective life-long learners.

The learner-centered approach provides much benefit, below the most cited in our readings:

- Enables personalized learning and Advances participation : traditional online courses treat all learners in the same way, and could not react to the different features of learners. Adopting the learner-centered approach, additional materials are included to ensure personalized and convenient contents and thereby enhance participation.

- Increases retention of knowledge: The learner-centered approach shifts the emphasis from traditional Learning to Learning with more engaging and simulating content.

- Improves problem-solving skills: the contents may have tests and games relating real life problems, which will lead learners to think and search of solutions.

- Encourages collaborative learnin: the learner-centered approach encourages learners to work together to solve problems, share learning and fosters teamwork.

The section above presents the two concepts Agile Learning Design and the learner-centered approach and gives some of their advantages. The section below will give some response to how can we integrate learner-centered approach into Agile learning design process to improve the teaching effectiveness, facilitate learning among students, and maximize motivation as well as reducing the dropout rates?

\section{AGILE CENTERED-LEARNING DESIGN: INTEGRATING LEARNER-CENTERED APPROACH INTO} AGILE LEARNING DESIGN APPROACH

As the proliferation of content, online courses and leaning activities is increasingly significant, learners must take an effective role and be agents for change by taking part of their learning. They must no longer keep up with the change neither be receptive agents who expect their teachers to transmit the knowledge. They must be more productive by participating in the construction of their knowledge and competencies and creating new opportunities for themselves.

According to Prensky[18], Many authors underlined that the didactical formula based on lectures where the teacher teaches (teacher telling or talking or lecturing) and students learn is not more adequate: the new paradigm fostered by the use of technologies is "students teaching themselves with teacher's guidance" [18].

In line with above, Stewart[19], states that learner have to participate actively to the learning process, that is they have to discuss, to read, to write, but also to solve problem, to analyze, to evaluate and to synthesize. To be active, students have to do things in addition to think about the think they are doing; moreover, to be cooperative students have to participate in tasks as a group.

Therefore, the new role of instructors is facilitator of learning and training. They have to attract all learners, guide and emphasis on debate along courses. As far as the learners are concerned, they have to be cooperative contributors not only listeners.

As we can see, the learner-centered approach is in line with the practice of Agile Learning Design cited above (§II. B). Indeed, the two approaches have a lot of similarities such as focusing on learners and their needs; encourage communication and collaboration between learners and teachers, use adaptive and iterative processes to achieve goals.

However, some authors such Blomkvist[20] and fox[21] claimed that even if Agile learning Design and learnercentered design are compatible, there are some dissimilarities. As an illustration, we evoke the concept of learner involvement and the end-learner. Thus, in the learner-centered design, learners involved in the design process are the same learners that will interact with the system in last. For the agile learning Design, learners involved in the design 
process are not necessarily the end users of the system. This may affect the efficiency of the learning as the end learners are not those who were involved in the design process.

Blomkvist[20] presents three approaches to explain how learner-centered design may be integrating with Agile learning Design.

- Integrating learners-centered design practices into the agile development methodology.

- Apply Agile learning design practices into learner-centered design framework.

- Balanced combination of Agile learning Design and learner-centered design.

The study of the three approaches, lead us to choose the third one because it is in line with our goals. Indeed, it permits us to combine the most useful practices of the Agile learning Design and the learner-centered design to achieve the development of an ALS in which learners are part of the team of the design and at the same time they are the end learners.

\section{A. The Design of the framework}

\section{A CASE OF STUDY:}

The agile Learning Design method used to implement the framework is organized in main four phases (Design, Develop, test and evaluate). We notice that we use the same phases to design all the components of the framework. In the initial plan and design, we establish the initial content of the ALS. In this stage, we use as a starting point, an architectural design of the proposed system which is composed by three main components Fig.2.

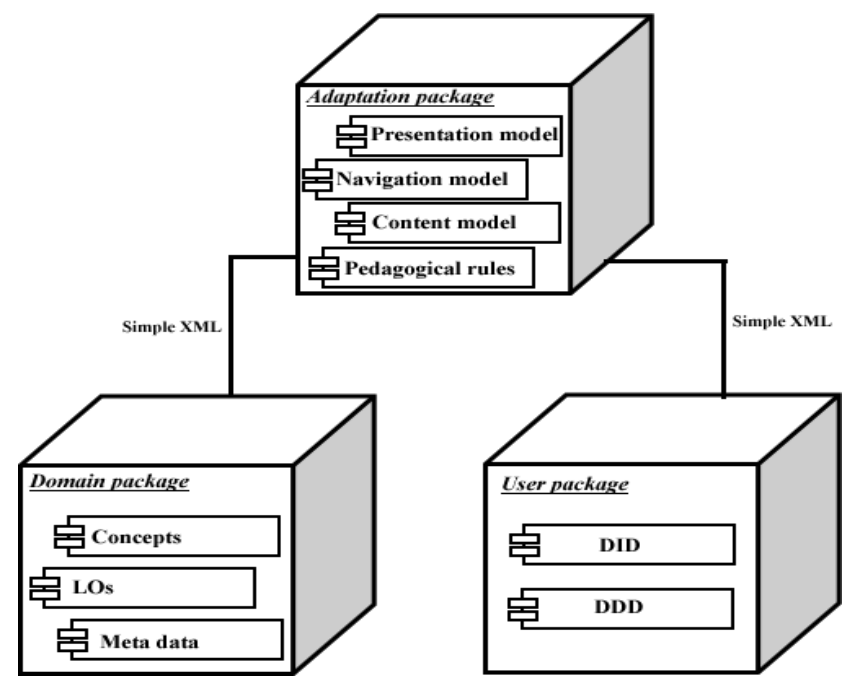

Figure 2. The framework architecture

In the following, we present these components, their descriptions, their features and interactions between them

a) The domain package: The domain package is characterized by its competence in terms of representation of concepts to learn, the resources available to learners and the structuring of various elements of the field.

b) The user package [19]: The user package allows changing several aspects of the system, in reply to certain characteristics (given or inferred) of the learner. It includes two type of information grouped in two domains

Domain Independent Data (DID and Domain Dependent Data (DDD)

c) The adaptation package: The adaptation package deals with the generation of adaptive content that will be subsequently presented to the learner. This component has four sub components: the navigation model, the presentation model, the content model and the pedagogical rules. Each sub-component contains a set of rules to achieve the adaptation.

After specifying the initial requirement and the main components of our system, every component was subject of a series of iterations, analyzing, designing, developing and testing each feature in turn. In the stage of testing we focused on remarks and feedbacks of learners. We collect all information that could be used to improve the succeeding sprint and to contribute to the constant enhancement process.

We notice that all data used in all stage of the design process, were collected through survey or during meeting. The next paragraph gives more details about the designing of the user package. 
B. The Design of User package[1]

The agile Learning Design method used to implement the user package is organized in four phases:

- Establish the initial content of the User package. In this stage, we use as a starting point, the User Model giving in generic AEHS that allows changing several aspects of the system, in reply to certain characteristics (given or inferred) of the user [22].

The User Model in AEHS includes two type of information grouped in two domains:

1. Domain Independent Data (DID): are composed of two elements: the Psychological Model and the Generic Model of the Student Profile, with an explicit representation [23]. These data are more permanent which allows the system to know beforehand which the characteristics that it must adapt to [24]. The DID include several aspects such initial user knowledge, objective and plans, cognitive capacities, learning styles, preferences, academic profile (technological studies versus economical studies and management, knowledge of literature, artistic capacities, etc.), etc.

2. Domain Dependent Data (DDD): information referring to the specific knowledge that the system judges that the user possesses on the domain. Martins [25] say that the components of the DDD correspond to the Domain Model with three-level functionality: (a) Task level, with the objectives / competences of the domain that the user will have to master. In this case, the objectives or intermediate objectives can be altered according to the evolution of the learning process; (b) Logical Level, which describes the user knowledge of the domain and is updated during the student's learning process; (c) Physical Level, that registers and infers the profile of the user knowledge.

Those two elements and theirs contents were discussed with prospective learners, and the member of our team to approve the initial architecture of the user package, presented below.

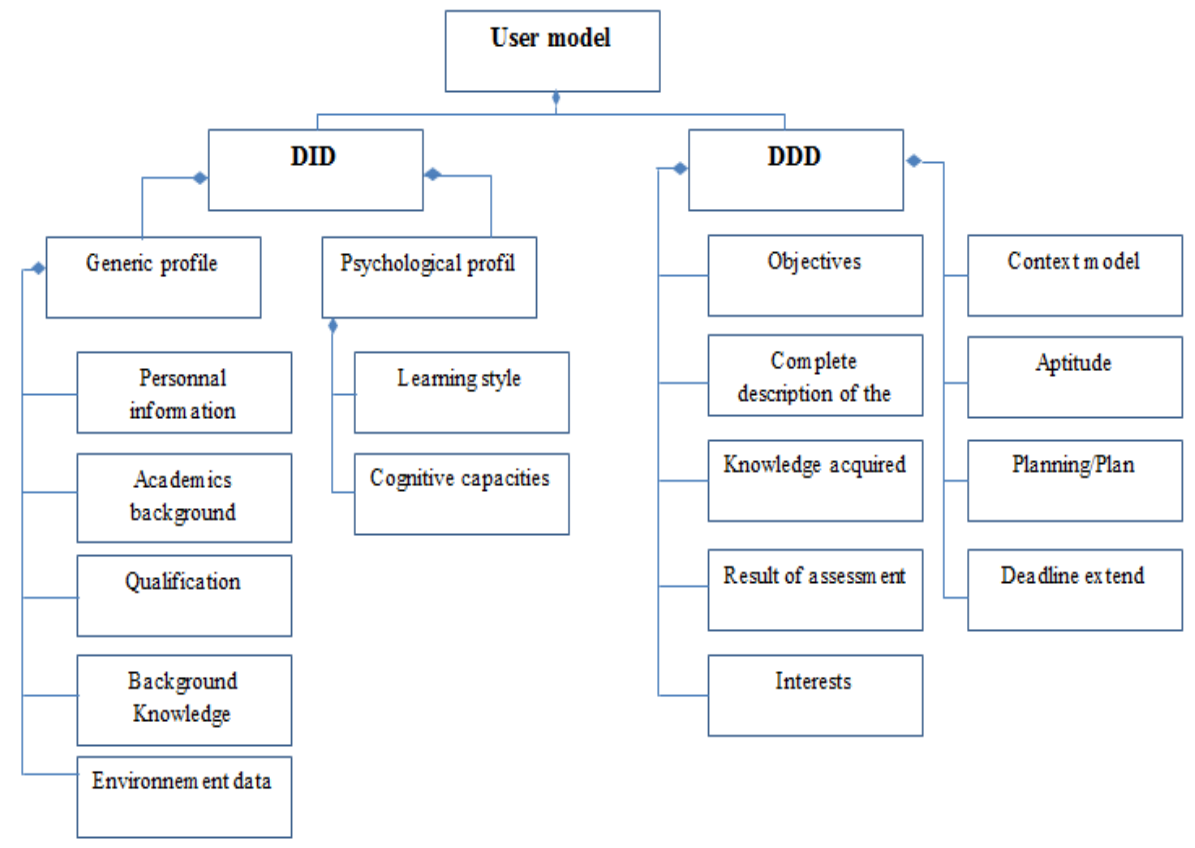

Figure 3. Characteristic used in the user package

- Plan and create the structure. In this stage, we agree the content of the user package in adequacy with our learning context. We highlight that we can refine this model (add or delete some content) since we can do iterative design.

-Implement the component. In this stage, we start the implementation, we agree the technologies that we will use to implement our user package and the design of the user interface.

Two different types of techniques are used to implement the Student Model: Knowledge and Behavioral based. The Knowledge-Based adaptation typically results for data collected through questionnaires and studies of the user, with the purpose to produce a set of initial heuristics. The Behavioral adaptation results from the monitorization of the user during his activity [25].

For the DID, we developed a form from which we will collect all the information about DID 
- Evaluate. In this step evaluates and approves the work. Some learners create their account in the component of tha user package, fill in the form and evaluate the initial version of the user package. In this stage, we focus on remarks and feedback of learners. We collect all information that ca be and used to improve the succeeding iteration and to contribute to the constant enhancement process.

\section{SOME RESULTS AND DISCUSS}

The first version of the framework presented in previous section, has already been implemented and tested to validate the proposed approach with some selected learners. As we work in faculty, we can't work in the stage of the design with much learner, especially with our first experience.

For the first version of the system we highlight that the Agile Learning Design method allows designs to be modified, repurposed and evolved according to the needs of learners emerging during development. In terms of the applicability of the method, the preliminary results indicate that the method is useful, easy to use. Furthermore, it focuses on the final client which is in our case the learners and their interactivity with the system

Another result is the human contact with the learners, they have not been considered without knowledge but rather partners who participate in the improvement of the system. This motivated them to give their best and develop further learning in the discipline.

At the end of the project, we conducted a survey that aimed to have the opinion of the learners on the new way to learn. We can highlight from the results of the survey that the most learners accepted the new learning model and expressed their satisfaction with the new learning experience. This lead us to believe that the implementation of those two approaches in the learning will surly diminish the dropout rate. Indeed, learners enjoy learning and give their best when they are involved in the learning experience and considered as partners not only listeners.

\section{IV.CONCLUSION}

In this paper we proposed a general view of how to support de design and the implementation of an ALS respecting the Agile Learning Design method and integrating the learner-centered approach. First, we expose the interest of integrating the learner-centered approach and using the Agile Learning Design. Furthermore, we present the preliminary results showing the success of this approach in designing and implementation of the components of ALS. We intend to complete our system and to enhance our proposal based on the results of the experiment and on the feedback from learners. For further validation, Firstly, we plan to embed more learners on the experiment of the all components of ALS, enhance our proposal based on the results of the experiment and on the feedback from those learners. Secondly, we plan to improve the proposal pedagogical model, including more materials to make learning more effective, amusing and attractive.

\section{REFERENCES}

[1] A,Battou, O. Baz, D.Mammass, "Toward a Framework for Designing Adaptive Educational Hypermedia System Based on Agile Learning Design Approach", Europe and MENA Cooperation Advances in Information and Communication Technologies Volume 520 of the series Advances in Intelligent Systems and Computing pp 113-123 (2016)

[2] M.Alshawi, J. Steven Goulding, I. Faraj, "KnowledgeBased Learning Environments for Construction", Journal for Education in the Built Environment, 1:1, 51-72 (2006)

[3] R. Retalis, A. Papasalouros, "Designing and Generating Educational Adaptive Hypermedia Applications". Educational Technology \& Society, 8 (3), 26-35. (2005).

[4] M. Grigoriadou, K. Papanikolaou, H. Kornilakis, G. Magoulas, “ INSPIRE: An INtelligent System for Personalized Instruction in a Remote Environment". In P. D. Bra, P. Brusilovsky, \& A. Kobsa (Eds.), Proceedings of Third workshop on Adaptive Hypertext and Hypermedia, July 14, 2001. Sonthofen, Germany, Technical University Eindhoven. - pp. 13-24 (2001).

[5] M.K. Stern, B.P. Woolf, "Adaptive content in an online lecture system", In P. Brusilovsky, O. Stock, \& C. Strapparava (Ed.), Adaptive Hypermedia and Adaptive Webbased systens (pp. 225-238). Berlin: Springer-Verlag. (2000).

[6] C. Süß, R. Kammerl, B. Freitag, “A teachware management framework for multiple teaching strategies”, In J. Bordeau, \& R. Heller (Eds.), Educational Multimedia/Hypermedia and Telecommunications, 1998, Proceedings of EDMEDIA'2000 - World Conference on Educational Multimedia, Hypermedia and Telecommunications, June 26 - July 1, 2000. Montréal, Canada, AACE. (2000).

[7] A. Battou, O. Baz, and D. Mammass, "Learning Design Approaches for Designing Virtual Learning Environments". Communications on Applied Electronics 5(9):31-37, September (2016)

[8] A. Battou, O. Baz, and D. Mammass, "Learning Design Approaches for Designing Learning Environments : A comparative study". 5th International Conference on Multimedia Computing and Systems - IEEE Conference . October (2016)

[9] H. Beetham, R. Sharpe ," An introduction to Rethinking Pedagogy, Rethinking pedagogy for a digital age : designing for 21 st century learning" $-2^{\text {nd }}$ edition 2013, pp. 26-35.

[10] G. Conole, "An overview of design representations", Proceedings of the 7th International Conference on Networked Learning 2010, Edited by: Dirckinck-Holmfeld L, Hodgson V, Jones C, de Laat M, McConnell D \& Ryberg T.

[11] R. Koper, "Current Research in Learning Design", Educational Technology \& Society, 9(1), pp.13-22. (2006)

[12] D. Clark, "Agile Learning Design: An Ethos for Creating Learning”, Training, and Performance Processes, September (2015). 
[13] M.M. Arimoto, L. Barroca, E.F. Barbosa , “An agile learning design method for open educational resources”. IEEE Frontiers in Education Conference Proceedings,IEEE, pp. 1897-1905, (2015).

[14] P. Blumberg, “ Developing Learner-Centered Teachers: A Practical Guide for Faculty”. San Francisco: Jossey-Bass. (2008)

[15] M.W. Matlin, "Cognitive psychology and college-level pedagogy: Two siblings that rarely communicate”. In D. F. Halpern, \& M. D. Hakel (Eds.), Applying the science of learning to university teaching and beyond. pp. 87-103. San Francisco: Jossey-Bass (2002).

[16] R.J. Sternberg, E.L. Grigorenko, "The theory of successful intelligence as a basis for instruction and assessment in higher education". In D. F. Halpern, \& M. D. Hakel (Eds.), Applying the science of learning to university teaching and beyond [The theory of successful intelligence as a basis for instruction and assessment in higher education] pp. 45-54. (2002).

[17] S. Mattheu, "A Proposal for an Agile Approach to the Teaching and Learning of Creative Technologies". A dissertation submitted to Auckland University of Technology in partial fulfilment of the requirements for the degree of: Bachelor of Creative Technologies (2013).

[18] M. Prensky, "The Role of Technology in Teaching and the Classroom". Educational Technology Nov-Dec (2008).

[19] C.J. Stewart, C.S. DeCusatis ,K. Kidder, J.R. Massi, and K.M. Anne, "Evaluating Agile Principles in Active and Cooperative Learning". Proceedings of Student-Faculty Research Day, CSIS, Pace University, May 8th, (2009)

[20] S. Blomkvist " Towards a model for bridging agile development and user-centered design". In Human-centered software engineeringintegrating usability in the software development lifecycle. pp. 219-244. Springer Netherlands. (2005).

[21] D. Fox, J. Sillito, \& F. Maurer "“ Agile methods and user-centered design: How these two methodologies are being successfully integrated in industry”. AGILE'08. Conference pp. 63-72. (2008).

[22] P. Brusilovsky “Adaptive hypermedia. User Modeling and User Adapted Interaction”, 11 (1/2), 87-110. (2001).

[23] A. Kobsa, "Generic User Modeling Systems". User Modeling and User-Adapted Interaction, 11 (1-2), 49-63. (2001).

[24] J. Vassileva, "A Task-Centred Approach for User Modeling in a Hypermedia Office Documentation System”. In Brusilovsky, P., Kobsa, A. \& Vassileva J. (Eds.), Adaptive Hypertext and Hypermedia, Dordrecht: Kluwer Academic, 209-247. (1998).

[25] A. C. Martins, L. Faria, C. Vaz de Carvalho, \& E. Carrapatoso, " User Modeling in Adaptive Hypermedia Educational Systems". Educational Technology \& Society, 11 (1), 194-207. (2008). 